\title{
Classification of commercial bitter orange essential oils (Citrus aurantium L.), based on a combination of chemical and sensory analyses of specific odor markers
}

\author{
Sophie C. Deterre, Barbara Rega, Julien Delarue, Eric Teillet \& Pierre \\ Giampaoli
}

To cite this article: Sophie C. Deterre, Barbara Rega, Julien Delarue, Eric Teillet \& Pierre Giampaoli (2014) Classification of commercial bitter orange essential oils (Citrus aurantium L.), based on a combination of chemical and sensory analyses of specific odor markers, Journal of Essential Oil Research, 26:4, 254-262, DOI: 10.1080/10412905.2014.917337

To link to this article: http://dx.doi.org/10.1080/10412905.2014.917337

Published online: 28 May 2014.

Submit your article to this journal $₫$

Џ Article views: 179

Q View related articles $\sqsubset$

View Crossmark data $₫$ 


\title{
RESEARCH ARTICLE
}

\section{Classification of commercial bitter orange essential oils (Citrus aurantium L.), based on a combination of chemical and sensory analyses of specific odor markers}

\author{
Sophie C. Deterre, Barbara Rega, Julien Delarue, Eric Teillet and Pierre Giampaoli* \\ AgroParisTech, Ingénierie Procédés Aliments, Massy, France
}

(Received 3 July 2012; accepted 7 April 2014)

\begin{abstract}
Ten commercial cold-pressed Citrus aurantium L. essential oils (EOs) were previously classified according to their content in twenty-seven key odorants as measured by gas chromatography-mass spectrometry (GC-MS). Principal component analysis and hierarchical cluster analysis performed on odor markers and composition data made it possible to distinguish five EO groups. In addition to chemical measurements, thirty-one subjects participated in a sensory analysis of the sample odors and classified the ten EO samples by means of a free-sorting task. The very good correlation found between chemical and sensory measurements made it possible to confirm that the odor markers previously identified using GC-olfactometry were effective indicators of the EO overall odor. This method combining instrumental and sensory analyses thus appears promising for discriminating and classifying EOs from a given botanical species.
\end{abstract}

Keywords: bitter orange essential oil; odor volatile compounds; principal component analysis (PCA); hierarchical cluster analysis (HCA)

\section{Introduction}

In citrus products, flavor has a pronounced effect on consumer preference and purchase decision $[1,2]$.

As the flavor quality of natural products often results from the complex mixture of many odorous compounds, the comparison of products of varying qualities is challenging. It usually relies on chemical analyses that yield multidimensional data sets. The use of statistical methods, such as principal component analysis (PCA) and hierarchical cluster analysis (HCA), may substantially simplify the classification of many natural products, as reviewed by Tzouros and Arvanitoyannis [3]. Concerning citrus products, these authors reported in particular several studies attempting to correlate physical-chemical parameters and sensory properties by investigating the impact of several volatile molecules on the overall aroma of, for instance, orange juice.

However, it is worth noting that most studies dealing with the quality of orange aroma were only based on chemical analyses of flavor extracts and, in some cases, on a posteriori mathematical correlations with sensory attributes. To mention some examples, Carter et al. [4] demonstrated that the amount of total aldehydes was a significant analytical parameter correlating with orange juice flavor. Pino [5] applied a multiple linear regression approach on the amounts of five volatile compounds (limonene, linalool, $\alpha$-terpineol, myrcene and 2-hexanol) selected from seven molecules to explain the sensory differences among orange juice extracts. Elmore et al. [6] correlated the gas chromatography $(\mathrm{GC})$ profile of headspace extracts to the characteristic aroma of commercial brands of orange juice. Finally, by combining sensory assessment and classification methods, Jella et al. [2] classified grapefruit juice extracts in the correct preference category using only myrcene, caryophyllene, linalool and ${ }^{\circ}$ Brix as markers.

Nevertheless, very few studies on the classification of orange products based their analytical strategy on specific flavor volatiles that were previously identified as being representative of the characteristic orange odor. Based on earlier results showing the concentrations of five volatile compounds as significant in distinguishing between geographical locations, McHard et al. [7] carried out a relatively simple pattern recognition program and clearly discriminated between concentrated juices from Florida and Brazil. Shaw et al. [8] classified commercial orange juice products according to the composition in pre-selected volatile compounds. In that study, up to twenty-five volatile components in each processed juice type could be used, as they had previously been identified as influencing the citrus juice flavor. From this analysis, two terpene hydrocarbons (myrcene and limonene) were found to be important components for discriminating twenty-seven juice samples.

*Corresponding author. Email: pierre.giampaoli@agroparistech.fr 
Lin et al. [9] applied an iterative strategy to evaluate natural sweet orange aroma samples in three steps: (i) sensory evaluation, (ii) identification and quantification of the aroma constituents by GC coupled with mass spectrometry (GC-MS), and (iii) the use of a computational profiling of sensory and instrumental data. Thanks to these three steps, samples with different compositions and flavor attributes could be separated into different categories.

Concerning bitter orange essential oil (EO), coldpressed orange peel oil and orange essence oil have not been well characterized in the past few decades because of unsuitable methods for routine quality control analysis [10] or unknown compounds [11]. In particular, Mayfield et al. [11] implemented a computational profiling method to treat chromatographic data of bitter and sweet orange peel oils and orange essence. In this way the authors succeeded in identifying four main constituents that are important in classifying samples: (E)-2-hexenal, terpinene-4-ol, a polyunsaturated hydrocarbon and a dicyclic sesquiterpenoid.

According to the ISO norm 9844 [12], bitter orange EO is characterized by some organoleptic and physical-chemical properties together with the presence of twelve volatile compounds in the proper percentages ( $\alpha$-pinene, $\beta$-pinene, myrcene, limonene, linalool, linalyl acetate, geranyl acetate, $\beta$-caryophyllene, germacrene $\mathrm{D},(Z)-\beta$-nerolidol, octanal and decanal). The amounts of these marker compounds can be different in the EOs from three different geographical zones: American, Equatorial and Mediterranean areas. Chialva et al. [13] and Kirbaslar and Kirsbaslar [14] proved that geographical origin is one of the sources of variation in EO composition. However, even if bitter orange EO is a fragrance/flavoring, the choice of these twelve volatile compounds in the ISO norm 9844 until now has not clearly been based on any sensory analysis data.

The aim of the present study was to investigate an adaptive and innovative methodology that combines chemical and sensory criteria to classify commercial bitter orange (Citrus aurantium L.) EOs issued from different suppliers, according to their odors. Twentyseven volatile compounds were found to significantly contribute to the overall character of bitter orange EO by $\mathrm{GC}$ and olfactometry (GC-O) [15]. These twenty-seven compounds, which include the reference compounds from the ISO 9844 norm (except (Z)- $\beta$ nerolidol), were thus used in the present study, as they provide more information than the current ISO list of molecules and they were specific to the odor of bitter orange EOs. We will present how these selected chemical volatiles provide a clear classification of EOs from different geographical origins. A comparison with the results of a sensory analysis of the EO global odors will then allow us to verify the pertinence of that classification. The methodological and analytical perspectives opened by these results are then discussed.

\section{Experimental}

\subsection{Samples}

Ten commercial bitter orange (C. aurantium L.) EOs were purchased from different suppliers (Table 1). Each sample claimed to be from a specific geographic origin, although this information could not be verified, as we did not obtain them directly from local producers.

Samples were stored in glass bottle in the dark at $4^{\circ} \mathrm{C}$.

\subsection{Chemicals}

Standards were obtained from the following sources: $\alpha$-pinene, $\beta$-pinene, camphene, myrcene, octanal, $\delta$-3carene, D-limonene, $\gamma$-terpinene, linalool, $\alpha$-terpineol, decanal, citral ( $E$ and $Z$ ), linalyl acetate and geranyl acetate were all purchased from Sigma-Aldrich (Saint-Louis, MO, USA). Ocimene, linalool oxyde (isomers), terpinolene, nonanal, terpinen-4-ol were obtained from Fluka (Buchs, Switzerland). Solutions of the standards were prepared with distilled water and absolute ethyl alcohol as solvents, purchased from Grosseron (Saint-Herblain, France) and Carlo-Erba

Table 1. Commercial bitter orange essential oil (EO).

\begin{tabular}{lll}
\hline Code sample & Declared origin of the EO & Supplier \\
\hline A & West Indies & Private source, The West Indies \\
B & Ivory Coast & Touraco, the Ivory Coast \\
C & Italy & Sensient, Germany \\
D & Brazil & Treat PCL, USA \\
E & Brazil & Copeland, England \\
F & Mixture of EO from South America and Africa & Copeland, England \\
G & Dominican Republic & Citrus and Allied, USA \\
H & Ivory Coast & Berjé, USA \\
I & Brazil & Berjé, USA \\
J & India & Katyani, India \\
\hline
\end{tabular}


(Rodano, MI, Italy). Internal standards for quantification, tridecane and nonane (for analyses $\geq 99 \%$ ) were purchased from Sigma-Aldrich.

\subsection{Selection of the key odor markers}

Twenty-seven volatile compounds were chosen as molecular markers of bitter orange EO odor. They include seven terpene hydrocarbons, four sesquiterpene hydrocarbons, ten aldehydes, three terpenic alcohols, two esters and one oxide. The list is given in Table 2.

\subsection{Identification and quantification of the key odor markers in commercial bitter orange $\mathrm{EO}$ samples}

An Agilent Technologies 6890 GC (Agilent Technologies, Santa Clara, CA, USA) interfaced with an inert mass selective detector was used to identify the volatile compounds. A fused silica capillary column was used with helium carrier gas (flow rate $1 \mathrm{~mL} / \mathrm{minute}$ ): an apolar capillary DB-5 column (5\% diphenyl / 95\% dimethyl siloxane) column, $30 \mathrm{~m}, 0.320 \mathrm{~mm}$ I.D., $0.5 \mu \mathrm{m}$ film thickness (from J\&W Scientific, Folsom, CA, USA). Samples were injected by using a GERSTEL MPS2 autosampler (GERSTEL GmbH\&Co. KG, Mülheim an der Ruhr, Germany).

The injection conditions of the EO samples were in split mode (split ratio 1:50; inj. volume: 0.1 $\mathrm{L}$ ).

For the purposes of quantification, internal standards solutions of nonane and tridecane were prepared at two concentrations using pentane as a solvent. The pentane base was added to the EO. A solution of the above-mentioned standards was then injected to determine their response factor. All samples were analyzed in triplicate.

The oven conditions were as follows: $65^{\circ} \mathrm{C}$ (held for 4 minutes), increased at $3^{\circ} \mathrm{C} /$ minute to $130^{\circ} \mathrm{C}$, increased at $5^{\circ} \mathrm{C} /$ minute to $240^{\circ} \mathrm{C}$ and then increased at $7^{\circ} \mathrm{C} /$ minute to $270^{\circ} \mathrm{C}$ (held for 10 minutes). The injector and detector temperatures were $250^{\circ} \mathrm{C}$. Mass spectra were recorded in the electron impact mode at $70 \mathrm{eV}$, with an ion source temperature of $250^{\circ} \mathrm{C}$. Full-scan data acquisition was registered over the range $\mathrm{m} / \mathrm{z}$ $40-400$ at 0.63 scans/second.

The software MSD ChemStation Data Analysis (Rev D) from Agilent was used for control, general operations and data acquisition of the results.

Mass spectral matches were made by comparing experimental mass spectra with those of the Wiley 7 and NIST 05 Libraries. Moreover, experimental retention indices were also determined for all constituents by injecting a homologous series of $n$-alkanes $\left(\mathrm{C}_{5}-\mathrm{C}_{28}\right)$ into the chromatographic column and they were then compared with the values given in the literature to confirm identification [15]. For some compounds of potential interest, both the experimental linear retention index $\left(I^{\mathrm{T}}\right)$ and the mass spectrum were compared with those from the pure standards injected to confirm peak assignment.

\subsection{Descriptive sensory analysis on commercial bitter orange $\mathrm{EO}$ samples}

The free sorting method [16] was used to classify the ten EO samples by their odor. This time-effective method requires minimum or no training and no specific language development, and it does not involve a quantitative rating system. It is appealing in that it is easy to perform, rapid and produces little fatigue or observer boredom [16].

The ten EO samples were placed at room temperature 1 hour before the session start. Five milliliters of each EO were poured into clear polypropylene cups (a 30-mL graduated cup with an airtight lid, supplier Pro'Jet France) and coded with a letter.

Thirty-one subjects, including students and professors, participated in a single evaluation session on the ten bitter orange EOs. The session was organized on only one day from 9 a.m. to noon and the sensory evaluation took place in a quiet environment at room temperature $\left(\sim 20^{\circ} \mathrm{C}\right)$.

Each subject was given a tray with the ten coded EOs. Verbal instructions were given on the task to perform. The subjects were asked to focus on the sample odor only and not to consider the visual differences they might perceive. Subjects were instructed to open the cup, smell the EO and then to close the cup. They had to group the samples that had similar odors. No limitations were given regarding the number of groups to be made. Subjects were allowed to smell EO samples as many times as necessary. Individual group data were collected by the experimenter and pooled at the panel level in a matrix of co-occurrence.

\subsection{Data analysis}

PCA was performed on the chemical compositions and HCA was carried out on the PCA matrix of the chemical data.

The co-occurrence matrix of the free sorting results indicated for each pair of EO samples the number of subjects who put them in the same group: the higher the number, the more similar the EOs. From this matrix, a dissimilarity matrix was deduced and then submitted to an HCA in order to classify the EO samples. A Mantel's test was performed to determine the correlation between the chemical-based and the sensory-based matrices of proximity resulting from the HCA. 
Journal of Essential Oil Research

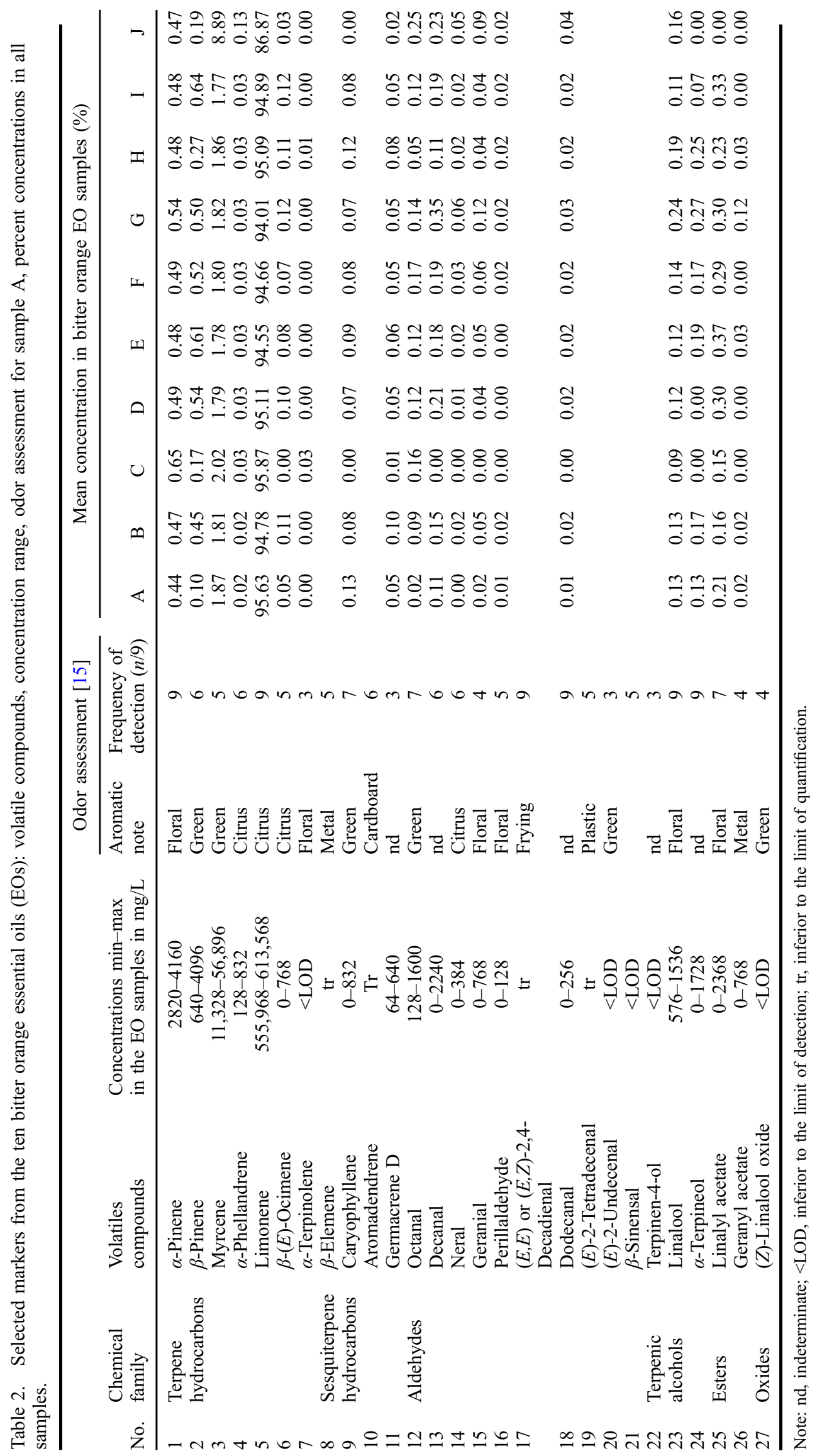


Analyses of variance (ANOVA) were run for statistical significance of differences in quantity for each odor marker. The level of significance was chosen as $p<0.05$. All analyses were performed with XLSTAT (Addinsoft XLSTAT v 2010.5.01).

\section{Results and discussion}

\subsection{Chemical composition}

Of the twenty-seven odor markers chosen according to the previous data on bitter orange $(C$. aurantium L.) EO [15, 17], eighteen molecules could be quantified from the ten bitter orange EOs beyond the limit of quantification/detection. All comprised the ISO norm 9844 [12] compounds, except the (Z)- $\beta$-nerolidol: six terpene hydrocarbons, two sesquiterpene hydrocarbons, six aldehydes, two terpenic alcohols and two esters (Table 2).

The composition results of the ten EO samples were compared with those found in the literature and close percentages were found for samples according to their declared geographical origin. However, some differences were pointed out.

The composition of sample A, from the West Indies, can be compared with the composition of the EO from Cuba described in Pino's study [18]. Sample A, even if displaying overall lower percentages of compounds than the sample studied by Pino et al. [18], was characterized by specific odor markers that were not previously reported in that study: $\alpha$-phellandrene $(0.02 \%), \quad \beta$-(E)-ocimene $\quad(0.05 \%), \quad$ perillaldehyde $(0.01 \%)$, linalyl acetate $(0.21 \%)$, octanal $(0.02 \%)$ and decanal $(0.11 \%)$.

Sample C, which is an EO of declared Italian origin, contained lower amounts of linalool and linalyl acetate than samples from the same country previously studied by Dugo [19] and Dugo et al. [20] [linalool: $0.09 \%$ in sample C, $0.270 \%$ in ref. [19] and $0.30 \%$ in ref. [20], and linalyl acetate: $0.15 \%$ in sample C, $0.894 \%$ in ref. [19] and $0.81 \%$ in ref. [20]].

Samples B and H, of declared Ivory Coast origin, contained more $\alpha$-terpineol $[0.17 \%$ in sample B, $0.25 \%$ in sample $\mathrm{H}$ and $0.081 \%$ in ref. [19]] and linalyl acetate $[0.16 \%$ in sample $\mathrm{B}, 0.23 \%$ in sample $\mathrm{H}$ and $0.07 \%$ in ref.[19]], but equivalent percentages of linalool than the samples analyzed by Dugo [19] $[0.13 \%$ in sample B, $0.19 \%$ in sample $\mathrm{H}$ and $0.101 \%$ in ref. [19]].

Finally samples D, E, F and I, of Brazilian declared origin, were comparable with the EO compositions found by Dugo [19] for a similar geographic origin. Even if composition values of alpha-terpineol and linalyl acetate were similar, the samples had lower amounts of linalool $[0.12 \%, 0.12 \%, 0.14 \%$ and $0.11 \%$ respectively, compared with $0.21 \%$ in ref. [19]].
It is worth noting that the differences in composition can be due not only to geographical origin but also to the degree of ripeness of the peels containing the EO [21-31] and to the method of EO extraction [32]. As all these factors are not controlled or known when dealing with commercial samples, it is difficult to discriminate samples in a reliable way according to these criteria. It clearly appears that a more broad classification method should be proposed to rapidly discriminate samples of different/unknown origin on the base of both chemical and odor markers, which could easily fulfill given quality product specifications.

\subsection{Classifications of the EOs according to their odor markers}

A PCA was performed on the composition data relatively to the pool of the 19 odor markers previously quantified in the ten EO samples (Figure 1). The contributions of the axes showed that the first four represented with $90 \%$ of the data.

The representation observed on the first two axes (representing $70.33 \%$ of total information) shows the main differences among the EO samples in terms of composition in odor markers. The most interesting point to note is that samples $\mathrm{B}, \mathrm{A}, \mathrm{H}, \mathrm{D}, \mathrm{E}, \mathrm{F}$ and I are grouped together and so not clearly distinguishable through their composition. Effectively, they seem all being characterized by sesquiterpene hydrocarbons, linalyl acetate, limonene, $\beta$-pinene, $\alpha$-terpineol and $\beta$-(E)-ocimene.

On the other hand, samples $\mathrm{C}, \mathrm{G}$ and $\mathrm{J}$ are spread and thus strongly discriminated from the others due to the amounts of specific compounds. In particular, sample $\mathrm{C}$ (declared Italian origin) is characterized by amounts of $\alpha$-terpinolene and $\alpha$-pinene, sample $\mathrm{J}$ (declared Indian origin) by the presence of myrcene, $\alpha$-phellandrene and octanal, and sample G (Dominican Republic declared origin) by the presence of decanal, geranial, perillaldehyde, neral, dodecanal, linalool and geranyl acetate.

With the most representative axes of the PCA (selected from the matrix of the square cosinus data), an HCA was performed and five groups of EO could be distinguished according to their compositions in odor markers (Figure 2).

Samples J, C and G are clearly discriminated into three separate groups as already observed by PCA analysis. However, HCA distinguishes two further groups: a group composed of D, E, F and I samples, and a third group composed of B, A and $\mathrm{H}$ samples. In order to deeply characterize these two groups, a further PCA was performed on composition data but excluding the most different EO samples (C, G and J) (Figure 3). 


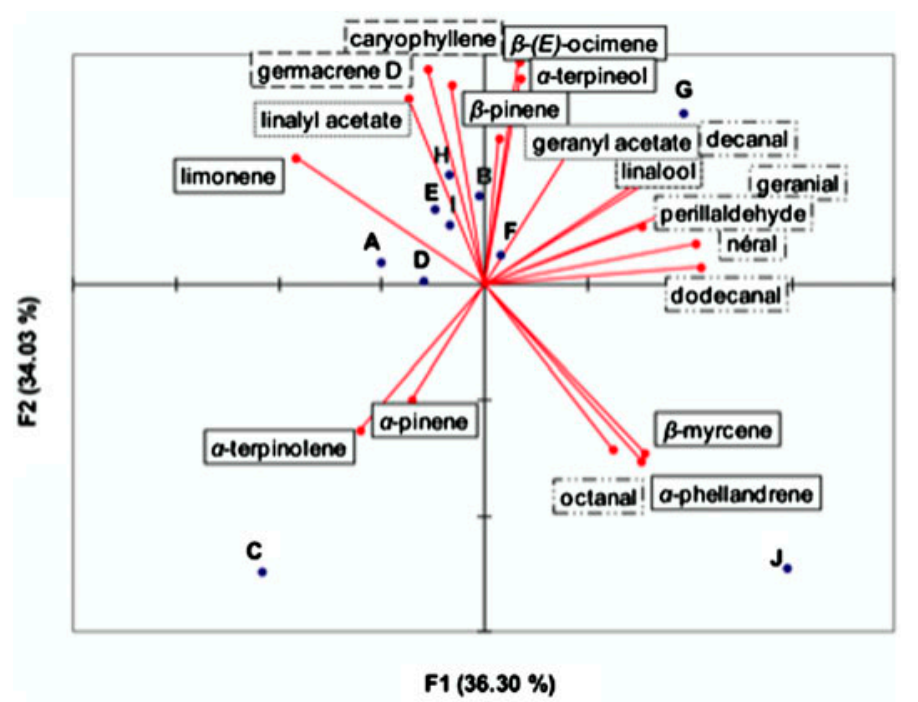

Figure 1. Principal components analysis of ten bitter essential oil samples according to nineteen volatile chemical markers concentration. ( $\_$terpene hydrocarbons; - - - sesquiterpene hydrocarbons; -..-.- - aldehydes; - - - - terpene alcohols; - esters).

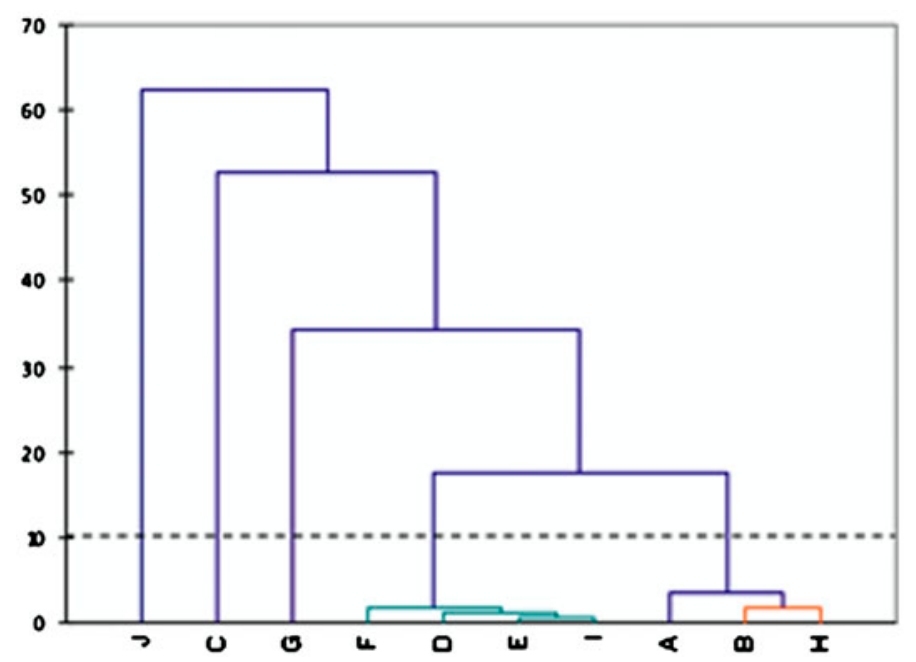

Figure 2. Dendrogram of the distance of the essential oils according to the odor markers composition (in concentration).

The distribution observed with the first two axes (representing $74.30 \%$ of the observation) made it possible to discriminate more clearly the most similar samples in the two main groups The group composed of $\mathrm{D}, \mathrm{E}, \mathrm{F}$, and I samples is characterized by the presence of linalyl acetate, decanal, $\alpha$-phellandrene, $\beta$-pinene, octanal, $\alpha$-pinene, dodecanal, neral, $\beta$ - $(E)$-ocimene and geranial. The group of samples $\mathrm{B}, \mathrm{A}$ and $\mathrm{H}$ displays the opposite tendency and is the same as that identified by the overall HCA analysis. It is worth noting that sample A (of West Indian origin) could be included in this group because of its high levels of limonene. It thus appears that each group is characterized by a short list of odor markers and could be also related to a geographic region in the case of products of certified origins.

\subsection{Classifications of the EOs according to their odor}

In parallel to chemical measurements, a sensory analysis assessment on sample odors was carried out by means of a free sorting method performed with thirtyone subjects. The purpose was to group together EO samples with similar odors. Hence, each group corresponded to one odor. On average, subjects classified the ten EOs into $4.7( \pm 1.4)$ groups. Subjects took about 5 minutes to complete the task. Some subjects 


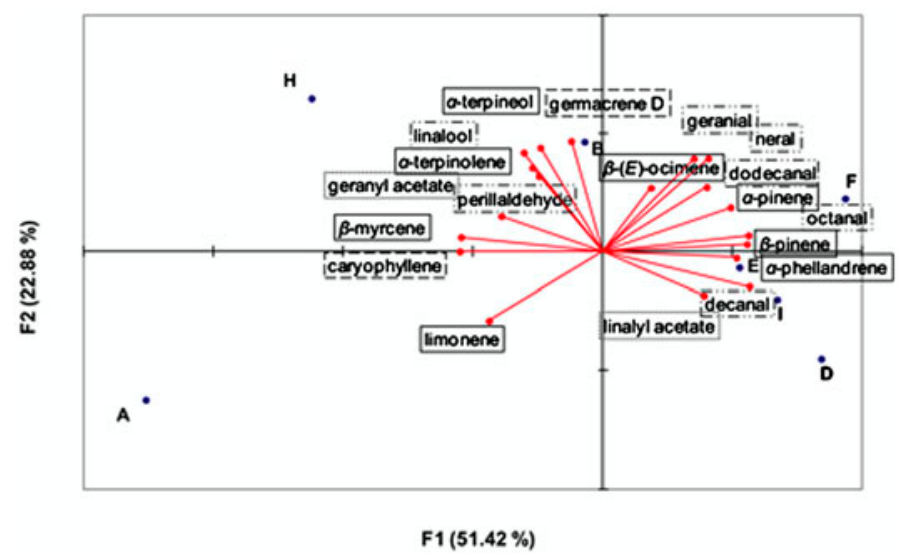

Figure 3. Principal components analysis of seven bitter essential oil samples according to nineteen volatile chemical markers concentration.

commented on their choices of the EO groups with odor descriptors, such as solvent, peel, green, thyme, rosemary, mandarin, indeterminate, pleasant and unpleasant odorant notes. Based on these sensory results, a matrix of dissimilarity and an HCA were performed to classify the EOs (Figure 4). Three groups are clearly distinguishable.

Samples B and $\mathrm{H}$ were in the same group, which corresponded perfectly to their similar chemical compositions (Figure 2) and to their nominal geographical origin (both from the Ivory Coast).

In contrast to the PCA, based on chemical composition, sample A is now gathered with a second group composed of samples of nominal American origin (E, $\mathrm{F}$ and I). This result could be explained by the low odor impact of limonene. It is well known that limonene is not the main contributor to the odor of EOs but it mainly plays a role of carrier for other key oxygen-

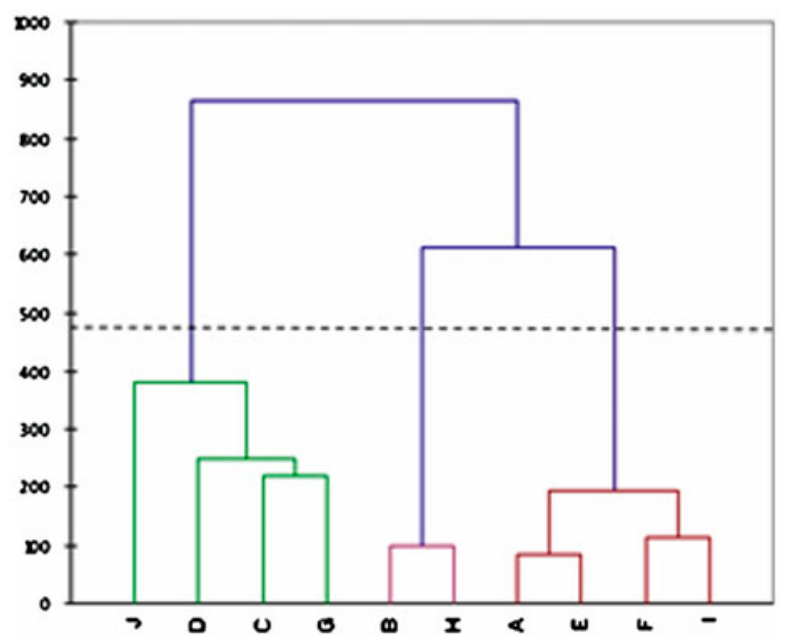

Figure 4. Dissimilarities of ten bitter orange essential oils classified by thirty-one panelists. ated compounds [33]. During free sorting, only odor profiles and not the amounts of volatile markers are relevant factors; therefore, the high amount of limonene in A was not a relevant criterion under the sensory point of view.

In Figure 4, however, samples J, C, G and D were grouped together and separated from the other six. Subjects could have (i) grouped the four samples together because their odors were different from the others (described by some subjects with unpleasant notes), or (ii) separated the four samples into four groups because they had different odors. In both cases, they were in the same group in the sensory HCA, whereas they are considered different from the others regarding their geographical origins (Table 1) and their chemical compositions (Figure 2). We focused especially on sample $\mathrm{D}$ and tried to explain why it no longer belonged to the group of Brazilian EOs in the sensory classification.

Comparing the two HCA graphs (Figure 2 and 4), it seems that sample D presented a difference in odor from samples E, F and I, but it had the same chemical composition. Several factors could explain this observation, such as the amounts of specific odor markers, odors of trace compounds, ripeness of the bitter orange peels, types of extraction process and the initial selection of the odor markers.

Firstly, regarding the chemical compositions in the odor markers of these four samples (samples D, E, F and I), it can be noted that sample D had significantly less $\alpha$-terpineol than the other three samples (Table 2). The difference in this key marker amount might have an impact on the overall odor of the EOs.

Moreover, this difference in odor could also be explained by the trace odor markers that were not detected or quantified in GC-MS (Table 1): $\beta$-elemene, aromadendrene, $(E, E)$ or $(E, Z)$-2,4-decadienal, $(E)$-2-tetradecenal, $(E)$-2-undecenal, $\beta$-sinensal, terpinen-4-ol 
and (Z)-linalool oxide. Another method of screening should be used to identify all the odor trace compounds that could contribute to the overall odor of samples D, $\mathrm{E}, \mathrm{F}$ and I, such as two-dimensional GC-time-of-flight MS and the $\mathrm{GC}-\mathrm{O}$ analyses.

Secondly, among the factors of composition variability, the degree of ripeness and the type of EO extraction process hugely influence the composition of citrus EOs for a same variety of bitter orange. Details of these two factors could be helpful in pointing out the cause of the odor difference between sample D and samples E, F and I.

Thirdly, as the initial selection of the twenty-seven odor markers had been determined from a specific bitter orange EO composition from the West Indies [15], it is possible that different odor markers would have been considered with a bitter orange EO from a different country.

Nevertheless, thanks to the Mantel's test correlation $(R(\mathrm{~A}, \mathrm{~B})=0.483, p=0.001)$, we concluded that the instrumental and sensory HCA corresponded well to each other. Hence, our selection of the odor markers was relevant to reflect the general EO odor.

\section{Conclusion}

PCA using nineteen key markers of ten commercial bitter orange EOs classified them into five groups. Surprisingly, the groups of EOs obtained with the chemical and sensory results corresponded quite well both together and with the geographical origin, except for one EO. The original approach with chemical and sensory classifications made it possible to validate the relevance of the previous selection of odor markers as representative of the EO odors. This method thus demonstrated that odor can be evaluated through specific volatile compounds and become a quality parameter for classifying EOs from different suppliers.

Further studies to refine the analytical method, such as seeking trace compounds, may be carried out in order to strengthen the relevance of this method. This approach, combining instrumental and sensory analyses, can be expanded to classify EOs produced with different varieties or at different seasons or many other food products where the odor is a main criterion of discrimination. For example, it would be interesting to conduct such a study with samples of certified origins in order to identify origin-specific patterns or markers of odor quality.

\section{Acknowledgement}

We would like to thank Donald White, native English translator from the A.B.I.E.S. doctoral school, for his kind help in the writing of this article.

\section{References}

1. E. Maccarone, S. Campisi, B. Fallico, P. Rapisarda and R. Sgarlata, Flavor components of italian orange juices. Journal of Agricultural and Food Chemistry, 46, 2293 (1998).

2. P. Jella, R. Roussef, K. Goodner and W. Widmer, Determination of key flavor components in methylene chloride extracts from processed grapefruit juice. Journal of Agricultural and Food Chemistry, 46, 242 (1998).

3. N.E. Tzouros and I.S. Arvanitoyannis, Agricultural produces: Synopsis of employed quality control methods for the authentication of foods and application of chemometrics for the classification of foods according to their variety or geographical origin. Critical Review in Food Science and Nutrition, 41, 287 (2001).

4. R.D. Carter, B.S. Buslig and J.A. Cornell, Statistical inferences on processed orange juice quality from the 1972-73 and 1973-74 juice definition program. Processing of the Florida State Horticultural Society, 88, 358 (1975).

5. J. Pino, Analysis of cold-pressed orange oil and of the essential oil present in aqueous condensates obtained from orange juice concentration. Acta Alimentaria, 11, 1 (1982).

6. J.S. Elmore, K. Thompson, C.K. Howard, J. Bakker and N. Bratchell, Comparison of the aroma of a food with its gas chromatographic headspace profile using multivariate analysis. Food Quality and Preference, 5, 151 (1994).

7. J.A. McHard, J.D. Winefordner and S.F. Foulk, Comparison of trace-element contents of Florida and Brazil orange juice. Journal of Agricultural and Food Chemistry, 27, 1326 (1979).

8. P.E. Shaw, M.G. Moshonas and B.S. Buslig, Multivariateanalysis for classification of commercial orange juice products by volatile constituents using headspace gas-chromatography. ACS SYMPOSIUM SERIES, 596, 33 (1995).

9. J.C.C. Lin, S. Nagy and M. Klim, Application of pattern-recognition techniques to sensory and gaschromatography flavor profiles of natural orange aroma. Food Chemistry, 47, 235 (1993).

10. G.F. Gostecnik and A. Zlatkis, Computer evaluation of gas chromatographic profiles for the correlation of quality differences in cold pressed orange oils. Journal of Chromatography A, 106, 78 (1975).

11. H.Y. Mayfield, W. Bertsch, T. Mar and J.A. Staroscik, Application of chemometrics to the classification of orange essence oil varieties by GLC. Journal of High Resolution Chromatography \& Chromatography Communications, 9, 78 (1986).

12. ISO, In: Norme Internationale ISO/FDIS 9844. Edit., ISO, p. 11, AFNOR, Genève (2006).

13. F. Chialva, A. Ariozzi, D. Decastri, P. Manitto, S. Clementi and D. Bonelli, Chemometric investigation on italian peppermint oils. Journal of Agricultural and Food Chemistry, 41, 2028 (1993).

14. F.G. Kirbaslar and S.I. Kirbaslar, Composition of coldpressed bitter orange peel oil from Turkey. Journal of Essential Oil Research, 15, 6 (2003).

15. S. Deterre, B. Rega, J. Delarue, M. Decloux, M. Lebrun and P. Giampaoli, Identification of key aroma compounds from bitter orange (Citrus aurantium L.) products: essential oil and macerate-distillate extract. Flavour and Fragrance Journal, 27, 77 (2012). 
16. L.M. Nijssen, C.A. Visscher, H. Maarse, L.C. Willemsens and M.H. Boelens, Volatile Compounds in Food Qualitative and Quantitative Data. Bitter Orange Peel Oil, 7th edn. Toegepast Natuurwetenschappelijk Onderzoek, Ziest, The Netherlands (1996).

17. S. Issanchou, in Evaluation sensorielle, manuel méthodologique (Ed.: D. SSHA, F.), pp. 169, Techniques \& Documentation, Paris (1998).

18. J.A. Pino and A. Rosado, Composition of cold pressed bitter orange oil from Cuba. Journal of Essential Oil Research, 12, 675 (2000).

19. G. Dugo, The composition of the volatile fraction of the Italian citrus essential oils. Perfumers \& Flavorists, 19, 29 (1994).

20. G. Dugo, D. Sciarrone, R. Costa, I. Bonaccorsi, P. Dugo, L. Mondello, L. Santi and H.A. Fakhry, Characterization of oils from the fruits, leaves and flowers of the bitter orange tree. Journal of Essential Oil Research, 23, 45 (2011).

21. K.S. Kealey and J.E. Kinsella, Orange juice quality with an emphasis on flavor components. Critical Reviews in Food Science and Nutrition, 1, (1979).

22. S. Ranganna, V.S. Govindarajan and K.V.R. Ramana, Citrus fruits: Part II. Chemistry, Technology, and quality evaluation. B. Technology. Critical Reviews in Food Science and Nutrition, 18, 17 (1983).

23. P.E. Shaw and R.L. Coleman, Quantitative composition of cold-pressed orange oils. Journal of Agricultural and Food Chemistry, 22, 785 (1974).

24. S. Nagy, C.S. Chen and P.E. Shaw, Orange and tangerine juices. In: Fruit Juice Processing Technology, pp. 110, Auburndale, Florida, USA 1993.

25. J.A. Attaway, G.E. Alberding, R.W. Wolford and G.J. Edwards, Identification of alcohols and volatile organic acids from natural orange essence. Journal of Agricultural and Food Chemistry, 12, 118 (1964).
26. J.A. Attaway, A.P. Pieringer and L.J. Barabas, The origin of citrus flavor components-III. A study of the percentage variations in peel ans leaf oil terpenes during one season. Phytochemistry, 6, 25 (1967).

27. L.J. Swift, TLC-Spectrophotometric analysis for neutral fraction flavones in orange peel juice. Journal of Agricultural and Food Chemistry, 15, 99 (1967).

28. O. Boussaada and R. Chemli, Seasonal variation of essential oil composition of Citrus aurantium L. var. amara. Journal of Essential Oil Research, 10, 109 (2007).

29. M.H. Boelens and R. Jimenez, The chemical composition of the peel oils from unripe and ripe fruits of bitter orange, Citrus aurantium L. ssp. amara Engl. Flavour and Fragrance Journal, 4, 139 (1989).

30. P. Dugo, L. Mondello, E. Cogliandro, A. Cavazza and G. Dugo, On the genuineness of citrus essential oils. Part LIII. Determination of the composition of the oxygen heterocyclic fraction of lemon essential oils (Citrus limon (L.) Burm. f.) by normal-phase high performance liquid chromatography. Flavour and Fragrance Journal, 13, 329 (1998).

31. G. Dugo, A. Verzera, I. Stagno d'Alcontres, A. Cotroneo and R. Ficarra, On the genuineness of citrus essential oil. Part XLI. Italian bitter orange essential oil: composition and detection of contamination and additions of oils and terpenes of sweet orange and of lemon. Flavour and Fragrance Journal, 8, 25 (1993).

32. K.H. Can Baser and G. Buchbauer, Handbook of Essential Oils Science, Technology and Applications. Taylor \& Francis Group, Boca Raton (2010).

33. E. Guenther, In: The Essentials Oils 1. History, Production and Analysis. Edit. E. Guenther, pp. 85, Van Nostrand Reinhold Company, New York (1972). 